\title{
On critical hydrogen concentration for hydrogen embrittlement of $\mathrm{Fe}_{3} \mathrm{Al}$
}

\author{
A PRIYADARSHI and R BALASUBRAMANIAM* \\ Department of Materials and Metallurgical Engineering, Indian Institute of Technology, Kanpur 208 016, India
}

MS received 2 May 2001; revised 13 August 2001

\begin{abstract}
The critical hydrogen concentration for hydrogen embrittlement in iron aluminide, $\mathrm{Fe}_{3} \mathrm{Al}$ has been estimated $(0.42 \mathrm{wppm})$. The estimated critical hydrogen content has been correlated to structural aspects of the decohesion mechanism of hydrogen embrittlement.
\end{abstract}

Keywords. Iron aluminides; hydrogen embrittlement; critical hydrogen concentration; decohesion; mechanism.

\section{Introduction}

Iron aluminides based on $\mathrm{Fe}_{3} \mathrm{Al}$ and $\mathrm{Fe} \mathrm{Al}$ are candidates of high-temperature structural materials because of their excellent oxidation and sulphidation resistance. However, the main drawback of iron aluminides is their poor ductility at ambient temperature, which has limited its use as an engineering material. The origin of this poor ductility has been recognized to be hydrogen embrittlement (HE), i.e. to environmental embrittlement due to hydrogen generated from the reaction of aluminum in the alloy with water vapour (Liu et al 1989). The brittleness of iron aluminides has also been associated with their poor cleavage strength and grain boundary weakness (McKamey and Liu 1990). Several methods have been proposed to minimize HE like oxide coating (McKamey and Liu 1990), heat treatment (McKamey and Pierce 1993), and alloying with passivityinducing elements (Balasubramaniam 1996, 1997).

Iron aluminides based on $\mathrm{Fe}_{3} \mathrm{Al}$ exist in two crystal allotropic modifications, $\mathrm{DO}_{3}$ and $\mathrm{B} 2$. Generally, the fracture surface of embrittled intermetallics exhibits cleavage facets of $\{100\}$ type (Agarwal and Balasubramaniam 1996; Agarwal et al 1996), suggesting decohesion as the possible mechanism of HE. Hydrogen enters the material after adsorption on the surface and diffusion through the surface layer. In the BCC ordered structures of iron aluminide, the glissile dislocations are of the type $a<111\rangle$, which glide normally on $\{110\}$ slip planes. These dislocations are generally dissociated into partials of the type $a / 2$ $<111$, separated by an antiphase boundary (Baker et al 1991). It is possible for the leading partials (and also the trailing partials) gliding on two different slip planes to interact to form a dislocation of type $a<001\rangle$. The formation of $\langle 001\rangle$ dislocations would result in transgranular cleavage across the $\{100\}$ planes (Baker et al 1991). The

\footnotetext{
*Author for correspondence
}

role of hydrogen in this locking mechanism is also significant. In the presence of hydrogen, it has been shown that twice the normal amount of hydrogen can be transported by the mobile dislocations ( $\mathrm{Li}$ and Liu 1992). When the mobile dislocations are locked, hydrogen content on the $\{100\}$ planes increases and this provides conditions favourable for initiation of cracking. The accumulation of hydrogen on the $\{100\}$ planes of the aluminide would lead to initiation and propagation of cracking in planes closely associated with the $\{100\}$ planes (Balasubramaniam 1996). The reasons for the weakness of the material along the $\{100\}$ planes is not well understood and this must be related to the type of bonding that exists across the $\{100\}$ planes (Balasubramaniam 1996, 1997).

In all the theories of HE, a critical amount of hydrogen is required in order to initiate cracking. This parameter and its significance have not been addressed in iron aluminides. The present communication will address this important aspect of $\mathrm{HE}$ in iron aluminide, $\mathrm{Fe}_{3} \mathrm{Al}$.

\section{Estimation}

Chiu et al (1996) studied the environmental-assisted cracking of a $\mathrm{Fe}_{3} \mathrm{Al}$-based iron aluminide of composition $\mathrm{Fe}-28 \mathrm{Al}-5 \mathrm{Cr}-0 \cdot 5 \mathrm{Nb}-0 \cdot 5 \mathrm{Mo}-0 \cdot 2 \mathrm{C}-0 \cdot 2 \mathrm{~B}-0 \cdot 1 \mathrm{Zr}$ in $3 \cdot 5 \%$ $\mathrm{NaCl}$ solution (of $\mathrm{pH} 6 \cdot 5$ ). The specimens were annealed at $750^{\circ} \mathrm{C}$ for $1 \mathrm{~h}$ to obtain them in the $\mathrm{B} 2$ ordered state. The concentrations of diffusible hydrogen, which is responsible for $\mathrm{HE}$, were measured as a function of applied potentials by the electrochemical permeation technique (Chiu et al 1996). They also conducted slow strain rate tests (SSRT) and determined ductility as a function of applied potential. The estimated diffusible hydrogen concentration $\left(C_{\mathrm{d}}\right)$ and ductility as a function of potential (Chiu et al 1996) have been reproduced in figure 1. Ductility was maximum in the intermediate potential range. At highly anodic potentials, ductility was low due to cracking 
by anodic dissolution mechanisms, whereas at cathodic potentials, the low ductility has been related to HE (Chiu et al 1996). The potential corresponding to ductility maximum provides the condition of critical hydrogen concentration $\left(C_{\text {crit }}\right)$ and the potential is referred to as the critical potential $\left(E_{\text {crit }}\right)$. This philosophy has earlier been proposed and applied to determine critical hydrogen concentration for HE in Al-Li alloys (Yusheng et al 1995). At potentials more active to $E_{\text {crit }}$, HE plays an increasingly important role due to increasing amounts of hydrogen liberation on the surface. This is reflected in figure 1 by decreasing ductility with increasing cathodic potentials (with respect to $\left.E_{\text {crit }}\right)$. The estimated critical hydrogen content $\left(C_{\text {crit }}\right)$ from figure 1 is $0.42 \mathrm{wppm}$.

The estimated critical hydrogen concentration expressed in units of atppm is 23 atppm, from the known atomic weights of iron and hydrogen. It is seen that hydrogen has extremely high embrittling potential as it is possible for such low concentrations to cause embrittlement. However, it must be noted that the estimated critical concentration is nearly three orders of magnitude greater than dissolved hydrogen concentration $(0.02$ atppm) in the absence of stress in iron at room temperature (Hirth 1980). Therefore, the hydrogen concentration has to build up to the critical level, at some localized location in the material, in order to initiate cracking.

\section{Correlation with decohesion mechanism}

In order to gain additional insights into the atomistic nature of $\mathrm{HE}$, the observed macroscopic $C_{\text {crit }}$ would be correlated to the hydrogen distribution at the crystal structural level. Using the specimen dimensions utilized by Chiu et al (1996) $(15.88 \mathrm{~mm}$ gauge length and $2.95 \mathrm{~mm}$ diameter), the volume of the specimen is $108.54 \mathrm{~mm}^{3}$. From the known density, $6.72 \mathrm{~g} / \mathrm{cm}^{3}$ (Liu and Kumar

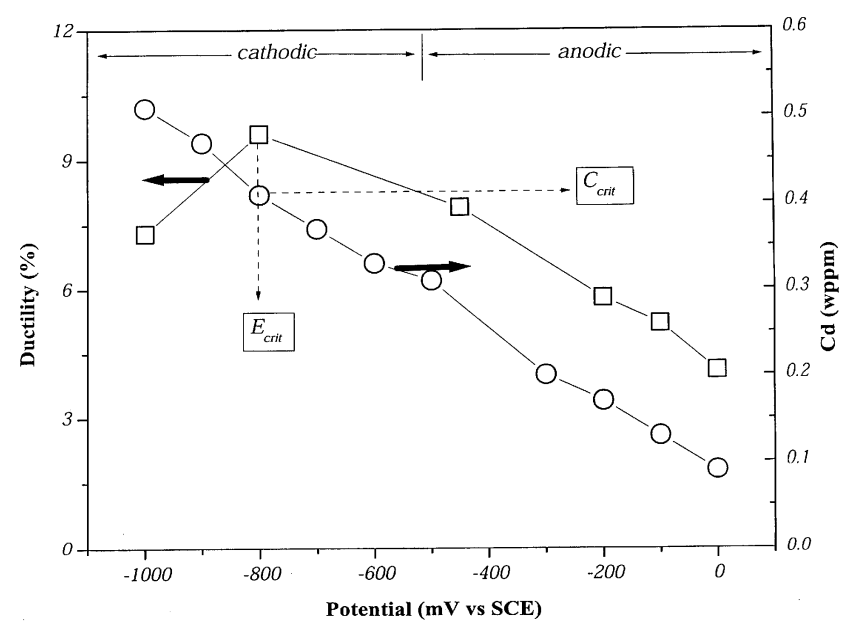

Figure 1. Relationship between critical hydrogen concentration $\left(C_{\text {crit }}\right)$ and critical potential $\left(E_{\text {crit }}\right)$ for hydrogen embrittlement in iron aluminide $\mathrm{Fe}_{3} \mathrm{Al}$ (Chiu et al 1996).
1993), and molecular weight (195 g), the number of moles of iron aluminide in the gauge length is $3.74 \times 10^{-3}$ mole. Therefore, the critical hydrogen concentration in the gauge length is $1.57 \times 10^{-9}$ moles (or $9.37 \times 10^{14}$ atoms). Chiu et al (1996) have also provided the potentiodynamic polarization curve for the iron aluminide in $3.5 \% \mathrm{NaCl}$ solution. The amount of hydrogen liberated on the surface can be determined utilizing the polarization data (i.e. from the known current density at the critical potential) and the total time taken for failure in the SSRT test at $E_{\text {crit }}$. The cathodic current density required to polarize the specimen to $E_{\text {crit }}\left(=-0.80\right.$ vs SCE) is $231 \mathrm{~mA} / \mathrm{cm}^{2}$ (Chiu et al 1996). The contribution of the oxygen reduction reaction to the applied current can be assumed insignificant because the limiting current density for oxygen reduction reaction is low (West 1970). As the applied strain rate was $10^{-6} \mathrm{sec}^{-1}$ in the SSRT and the strain to fracture was $9.63 \times 10^{-2}$, the total time of current flow was $9.63 \times 10^{4} \mathrm{sec}$. From the known current density and the time of current flow, a charge of $2.22 \times 10^{4}$ coulomb $/ \mathrm{cm}^{2}$ can be estimated. Utilizing this and the known electronic charge required to liberate one hydrogen atom, the total number of hydrogen atoms liberated can be estimated. This number, in terms of molar concentration of hydrogen, works out to be $0.23 \mathrm{~mole} / \mathrm{cm}^{2}$. As the specimen area in the gauge length is known $\left(1.47 \mathrm{~cm}^{2}\right)$, the total number of moles of hydrogen liberated is 0.34 moles $\left(2.04 \times 10^{23}\right.$ atoms).

It is necessary to understand the role of hydrogen within the material in causing HE. As the heat treatment of the iron aluminide provided the B2 structure, this structure shall be considered. The volume of one B2 unit cell is $2.46 \times 10^{-23} \mathrm{~cm}^{3}$ since the lattice parameter of $\mathrm{B} 2 \mathrm{Fe}_{3} \mathrm{Al}$ is $0.291 \mathrm{~nm}$. Therefore, the total number of unit cells in the gauge region of the specimen is $4.41 \times 10^{21}$ unit cells.

In the first case, all the liberated hydrogen atoms are considered to enter the specimen thereby ignoring the loss of hydrogen from the surface. In such a case, the number of $\mathrm{H}$ atom/cell would be 46 atoms/cell. A B2 unit cell cannot accommodate such large $\mathrm{H}$ contents and hence, this situation does not appear to be realistic. It is, therefore, clear that only a fraction of the hydrogen liberated on the surface enters the material to cause embrittlement.

In the second case, the filling of hydrogen on specific planes would be considered. As noted earlier, the fracture nature is cleavage along planes of $\{100\}$ type. Due to strain energy considerations, hydrogen can occupy only one tetrahedral interstitial site per $\{100\}$ plane in a unit cell (Balasubramaniam 1996). If it is assumed that HE occurs when all the diffusible hydrogen have occupied the interstitial sites on $\{100\}$ planes, the total number of hydrogen atoms in the interstitial sites on $\{100\}$ planes (in the material in the gauge section) can be estimated to be $2.65 \times 10^{22}$. It can be noted that this is lower than the calculated amount of hydrogen liberated $\left(2 \cdot 04 \times 10^{23}\right)$ on the surface of the material during the duration of the 
SSRT. However, this amount $\left(2.65 \times 10^{22}\right)$ is much larger than the critical hydrogen concentration, and therefore this case cannot be a realistic consideration of hydrogen embrittlement. It is therefore realized that diffusivity of hydrogen also has a role to play in determining site filling along the $\{100\}$ planes.

In the third case, it is assumed that HE takes place when the interstitial sites on $\{100\}$ planes in the central plane in the gauge length are filled with hydrogen. From the known specimen dimensions, the number of hydrogen atoms required to fill one site per cube $\{100\}$ plane is $5.50 \times 10^{14}$ atoms. It is realized that this amount of hydrogen atom is of a similar order as the diffusible hydrogen estimated earlier $\left(9.37 \times 10^{14}\right.$ atoms $)$. The time of diffusion of hydrogen into the specimen must also be considered. If $\mathrm{HE}$ is assumed to occur due to hydrogen filling of the $\{100\}$ planes in the central plane of the gauge section, then this amount of hydrogen must reach the central plane in the time of SSRT experiment. The diffusivity of $\mathrm{H}$ in $\mathrm{Fe}_{3} \mathrm{Al}$ at ambient temperature is known $\left(1.45 \times 10^{-13} \mathrm{~m}^{2} / \mathrm{sec}\right)$ (Balasubramaniam 1999). As the diffusion occurs from surface, where $\mathrm{H}$ concentration is maintained constant, the diffusion problem can be treated as unsteady diffusion through infinite plate for which

$$
\frac{C_{x}-C_{0}}{C_{\mathrm{s}}-C_{0}}=1-\operatorname{erf}\left(\frac{X}{2 \sqrt{D t}}\right) .
$$

In the above equation, $C_{x}$ is the concentration of hydrogen at a distance $X$ from the surface, $C_{\mathrm{s}}$ the surface hydrogen concentration, $C_{0}$ the initial hydrogen concentration, $D$ the diffusivity of hydrogen in the material and $t$ the diffusion time. It is assumed that the surface concentration, $C_{\mathrm{s}}$ is the diffusible hydrogen content (i.e. $9 \cdot 37 \times 10^{14}$ atoms). Moreover, $C_{0}=0, C_{x}=5.50 \times 10^{14}$ atoms (assuming one hydrogen per $\{100\}$ plane of each cell lying on the vertical specimen plane), and $X=1.48 \mathrm{~mm}$. The estimated time to attain the concentration $C_{x}$ in the middle of the specimen is $2.60 \times 10^{7} \mathrm{sec}$, which is much higher than the total experimental time $\left(9.63 \times 10^{4} \mathrm{sec}\right)$.

The above calculation shows that hydrogen does not have to reach and accumulate in the middle plane of the sample to initiate cracking. When hydrogen filling of the lattice occurs such that decohesion occurs in only a part of the sample, initiation of cracking takes place. Hydrogen atoms act directly at crack tip and the initiated crack quickly propagates through the matrix causing embrittlement. The crack propagation is fairly rapid. Fractographic features of iron aluminides allude to this mechanism of crack propagation (Agarwal and Balasubramaniam 1996). In this regard, the dynamic model of hydrogen assisted cracking can be compared with data on other material systems.

The formation of microcrack nucleus can be achieved by local deformation alone and this may be assisted by hydrogen. The critical stage in fracture, however, is the growth of this crack nucleus through the grain. Detailed fractographic observation of hydrogen embrittlement in FeSi and Ni single crystals and their modelling have provided that a high density of trapping sites is produced during crack growth at the tip and the filling of these sites with hydrogen controls embrittlement (Vehoff and Rothe 1983). Therefore, hydrogen assisted crack growth depends on concentration of hydrogen at these crack tip sites and this concentration is greater than at deep trapping sites (Vehoff and Klameth 1985). A large concentration of hydrogen at crack tip reduces cohesive forces (Oriani 1972). As the bonds at the crack tip extends and breaks under the high local stresses at the crack tip, the crack extends. Based on direct observation of hydrogen enhanced crack propagation in iron, it is also known that crack extension in the presence of hydrogen is accompanied by the emission of dislocations from the tip, dislocation generation in the cell structure ahead of the crack tip and also annihilation of dislocations (produced in the region ahead of the crack tip) by moving back to the crack tip (Tabata and Birnbaum 1984). It is important to note that the crack tip, however, is maintained sharp even at low levels of applied stress. Due to this atomically sharp crack being maintained, both during nucleation and growth, the enhancement of hydrogen solubility is maintained ahead of the crack tip (because of the large strain ahead of the crack tip). The motion of hydrogen ahead of the crack tip is much faster than bulk diffusion processes due to the high strain gradient ahead of the crack tip. The moving crack tip accumulates hydrogen by sweeping hydrogen dissolved in the lattice during the early stage of crack propagation, and the high hydrogen concentration is maintained ahead of the crack tip. Therefore, the embrittling atmosphere is carried by the moving crack. The subsequent growth of the crack is determined by Griffith-type energy balance criterion (Kameda and Jokl 1982). Based on the above discussion, it is clear that once the critical hydrogen concentration is attained, crack initiation and propagation occurs with relative ease.

\section{Conclusions}

The critical concentration for hydrogen embrittlement in iron aluminide, $\mathrm{Fe}_{3} \mathrm{Al}$ has been determined (diffusible hydrogen content of 0.42 wppm). Analysis of hydrogen filling of $\{100\}$ planes revealed that once a crack is initiated by decohesion in the near surface grains, further crack propagation should be relatively fast.

\section{Acknowledgement}

The authors would like to thank Dr D Banerjee for his probing questions which inspired us to undertake this study. 


\section{References}

Agarwal A and Balasubramaniam R 1996 Practical Metallography $\mathbf{3 3} 453$

Agarwal A, Balasubramaniam R and Bhargava S 1996 Metall. Mater. Trans. A27 2985

Baker I, Nagpal P, Liu F and Munroe P 1991 Acta Metall. 39 1637

Balasubramaniam R 1996 Scr. Mater. 34127

Balasubramaniam R 1997 J. Alloy Compds. 253-254 203

Balasubramaniam R 1999 J. Alloy Compds. 293-295 279

Chiu H, Qiao L and Mao X 1996 Scr. Mater. 34963

Hirth J P 1980 Metall. Trans. A11 861

Kameda J and Jokl M L 1982 Scr. Metall. 16325
Li J C M and Liu C T 1992 Scr. Metall. Mater. 271701

Liu C T, Lee E H and McKamey C G 1989 Scr. Metall. 23875

Liu C T and Kumar K S 1993 J. Metals 4538

McKamey C G and Liu C T 1990 Scr. Metall. Mater. 242119

McKamey C G and Pierce D H 1993 Scr. Metall. Mater. 28 1173

Oriani R A 1972 Ber. Bunsenges 76848

Tabata T and Birnbaum H K 1984 Scr. Metall. 18231

Vehoff H and Rothe W 1983 Acta Metall. 311781

Vehoff H and Klameth H K 1985 Acta Metall. 33955

West J M 1970 in Electrodeposition and corrosion processes (London: Van Nostrand Reinhold Co), 2nd ed. p. 56

Yusheng C, Ziyong Z, Sue K and Wei K 1995 Scr. Mater. 34 781 